severity of depression by HRDS ( $\mathrm{p}=0.0098)$, and the index of personal anxiety $(\mathrm{P}=0.009)$ in group 1 decreased. In the 2 nd group above mentioned parameters have not changed. On the 1 group data of SF-36 evaluation: the physical health component has improved - the increase of RP and BP $57.4 \%$ and $37.8 \%$ from the baseline; vital activity and role functioning due to emotional state, have also increased by $35.6 \%$ and $43.5 \%$, respectively. In the 2nd group $(n=22)$ investigated parameters have not undergone significant changes in dynamics. In the 1 receiving melatonin group TJC and SJC have decreased by $15 \%$ and $22 \%$ $(p=0.0079, p=0.0022$, respectively) and their dynamics in the 2 nd group was less significant $(p=0.013$ and $p=0.017$, respectively). Also, patients in group 1 have highly significant $(p<0.001)$ reduction in the severity of morning stiffness and joint pain, and in the 2nd group the changes were less significant (respectively, $p=0.043, p=0.016$ ). Positive dynamics of CRP in group 1 was more significant $(p=0.003)$, than it was in 2 patients' group $(p=0.033)$.

Conclusions: In the group of patients treated with melatonin was noted improvement in general condition (a significant improvement in the parameters of the physical components of health, reduction of depressive and psycho-vegetative disorders) and also more significant decrease of the intensity of pain and of morning stiffness duration, of TJC and SJC, than in not treated with melatonin patients. Inclusion of Melatonin in the comprehensive PsA therapy promotes not only reduction of depression symptoms and sleep disorders, but also reduces the severity of the chronic pain manifestations and, consequently, improves the quality of life of patients with this disease

Disclosure of Interest: None declared

DOI: 10.1136/annrheumdis-2017-eular.2378

\section{FRI0496 COMPARING TOFACITINIB SAFETY PROFILE IN PATIENTS WITH PSORIATIC ARTHRITIS IN CLINICAL STUDIES WITH REAL-WORLD DATA}

J.R. Curtis ${ }^{1}$, H. Yun ${ }^{1}$, O. FitzGerald ${ }^{2}$, K. Winthrop ${ }^{3}$, V.F. Azevedo ${ }^{4}$, G. Burmester ${ }^{5}$, W.F.C. Rigby ${ }^{6}$, K.S. Kanik ${ }^{7}$, R. Rojo ${ }^{7}$, S. Menon ${ }^{7}$, C. Wang ${ }^{7}$, P. Biswas ${ }^{8}$, T. Hendrikx ${ }^{9}$, N. Palmetto ${ }^{8} .{ }^{1}$ University of Alabama at Birmingham, Birmingham, AL, United States; ${ }^{2}$ Department of Rheumatology, St Vincent's University Hospital, Dublin, Ireland; ${ }^{3}$ Oregon Health and Science University, Portland, OR, United States; ${ }^{4}$ Universidade Federal do Paraná, Curitiba, Brazil; ${ }^{5}$ Charité - University Medicine Berlin, Berlin, Germany; ${ }^{6}$ Geisel School of Medicine at Dartmouth, Lebanon, NH; ${ }^{7}$ Pfizer Inc, Groton, CT; ${ }^{8}$ Pfizer Inc, New York, NY; ${ }^{9}$ Pfizer Inc, Collegeville, PA, United States

Background: Tofacitinib is an oral Janus kinase inhibitor under investigation for the treatment of psoriatic arthritis (PsA). Two Phase 3 studies have been completed (NCT01877668; NCT01882439) and a long-term extension (LTE) study is ongoing (database not locked; NCT01976364).

Objectives: To compare incidence rates (IR) for adverse events (AEs) of special interest in a tofacitinib cohort from the Phase 3 PsA trials with real-world experience in a comparison cohort from the US Truven MarketScan database.

Methods: The tofacitinib cohort included adult patients (pts) from 2 Phase 3 studies with $>6$ months PsA diagnosis who met CIASsification of Psoriatic ARthritis (CASPAR) criteria, had active plaque psoriasis, and active arthritis $(\geq 3$ swollen and $\geq 3$ tender/painful joints) and who were treated with tofacitinib. Pts were grouped by those who received tofacitinib $5(\mathrm{~N}=238)$ or $10 \mathrm{mg}(\mathrm{N}=236)$ twice daily (BID) in the 2 Phase 3 studies, and all pts who received $\geq 1$ dose of tofacitinib in the 2 Phase 3 studies or the LTE (tofacitinib all doses, N=783). The comparison cohort $(\mathrm{N}=5799)$ comprised pts with moderate to severe PsA, defined by $\geq 1$ inpatient or $\geq 2$ outpatient 696.0 diagnosis codes on 2 unique calendar days ( $\geq 1$ by a rheumatologist) between Oct 2010 and Sep 2015, initiating therapy with a systemic agent for PsA. Key Phase 3 study exclusion criteria were applied to the comparison cohort. IRs for serious infection events (SIEs), herpes zoster $(\mathrm{HZ})$, malignancies (excluding non-melanoma skin cancer [NMSC]), NMSC and major adverse cardiovascular events (MACE) were compared.

Results: Mean age, gender and diabetes history were generally similar between the tofacitinib and comparison cohorts (48.7-49.5 years, $42.4-49.2 \%$ male, $12.2-$ $15.7 \%$ with diabetes history). Overall more pts treated with tofacitinib had prior experience with corticosteroids (15.7-28.2\%), conventional synthetic diseasemodifying antirheumatic drugs (100\%) and tumour necrosis factor inhibitors (48.1-55.9\%) vs the comparison cohort $(11.9 \%, 46.6 \%$ and $36.6 \%$, respectively). IRs for SIEs were lower for the tofacitinib vs the comparison cohort (Table 1). The tofacitinib cohort had a higher rate of $\mathrm{HZ}$ vs the comparison cohort (Table 1). IRs for malignancies and MACE were similar between cohorts (Table 1).

Conclusions: IRs of AEs of special interest reported in tofacitinib PSA Phase 3 studies were generally comparable to those in a general PsA population comprising pts receiving a range of biologic agents, except $\mathrm{HZ}$, which was higher for pts treated with tofacitinb but similar to the incidence observed with tofacitinib treatment in other indications.

Acknowledgements: This study was sponsored by Pfizer Inc. Editorial support was provided by A Pedder of CMC and was funded by Pfizer Inc.

Disclosure of Interest: J. Curtis Grant/research support from: Amgen, BristolMyers Squibb, Eli Lilly, Janssen, Pfizer Inc, Consultant for: AbbVie, Amgen, Bristol-Myers Squibb, Eli Lilly, Janssen, Pfizer Inc, H. Yun Grant/research support from: Pfizer Inc, O. FitzGerald Grant/research support from: AbbVie, Bristol-Myers Squibb, Consultant for: Bristol-Myers Squibb, Eli Lilly, Janssen, Pfizer Inc, Speakers bureau: Celgene, Janssen, Novartis, K. Winthrop Grant/research support

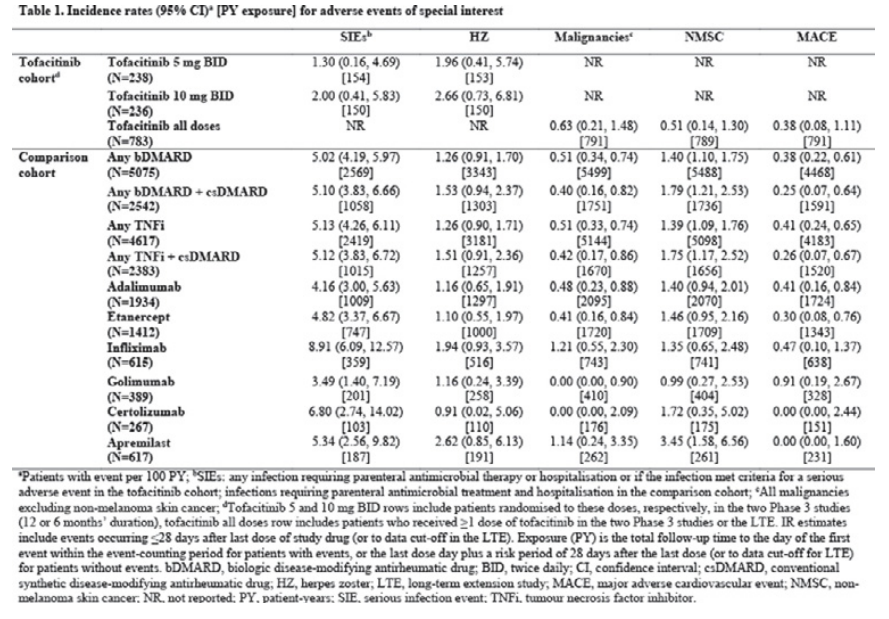

from: Bristol-Myers Squibb, Pfizer Inc, Consultant for: AbbVie, Amgen, BristolMyers Squibb, Eli Lilly, Galapagos, Pfizer Inc, UCB, V. Azevedo Grant/research support from: Bristol-Myers Squibb, GSK, Pfizer Inc, UCB, Consultant for: AbbVie, Bristol-Myers Squibb, Janssen, Merck Serono, Novartis, Pfizer Inc, G. Burmester Grant/research support from: UCB, Consultant for: AbbVie, Bristol-Myers Squibb, Eli Lilly, Hexal, Janssen, MSD, Medimmune, Novartis, Pfizer Inc, Sanofi, Roche, Speakers bureau: AbbVie, Bristol-Myers Squibb, Hexal, MSD, Novartis, Pfizer Inc, Roche, W. F. Rigby Grant/research support from: Amgen, Pfizer Inc, Roche, Consultant for: Bristol-Myers Squibb, Eli Lilly, Pfizer Inc, Roche, K. Kanik Shareholder of: Pfizer Inc, Employee of: Pfizer Inc, R. Rojo Shareholder of: Pfizer Inc, Employee of: Pfizer Inc, S. Menon Shareholder of: Pfizer Inc, Employee of: Pfizer Inc, C. Wang Shareholder of: Pfizer Inc, Employee of: Pfizer Inc, P. Biswas Shareholder of: Pfizer Inc, Employee of: Pfizer Inc, T. Hendrikx Shareholder of: Pfizer Inc, Employee of: Pfizer Inc, N. Palmetto Shareholder of: Pfizer Inc, Employee of: Pfizer Inc

DOI: 10.1136/annrheumdis-2017-eular.2448

\title{
FRI0497 WHAT CHOICES DO RHEUMATOLOGIST MAKE IN ESCALATING DMARD THERAPY IN EARLY PSA?
}

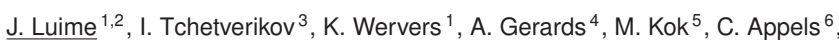
H. van Groenendael ${ }^{7}$, W. vd Graaff ${ }^{8}$, L.-A. Korswagen ${ }^{9}$, J. Veris ${ }^{10}$, M. Hazes ${ }^{1}$, M. Vis ${ }^{1}$ on behalf of Cicero. ${ }^{1}$ Rheumatology, ErasmusMC, Rotterdam; ${ }^{2}$ Data, Analytics and BI, Maxima Medisch Centrum, Veldhoven; ${ }^{3}$ Rheumatology, ASZ, Dordrecht; ${ }^{4}$ Rheumatology, Fransciscus - Vlietland, Schiedam; ${ }^{5}$ Rheumatology, Maasstadziekenhuis, Rotterdam; ${ }^{6}$ Rheumatology, Amphia, Breda;

${ }^{7}$ Rheumatology, Reumazorg zuidwest Nederland, Roosendaal; ${ }^{8}$ Rheumatology, Beatrix ziekenhuis, Gorinchem; ${ }^{9}$ Rheumatology, Franciscus, Rotterdam;

${ }^{10}$ Rheumatology, Reumazorg zuidwest Nederland, Goes, Netherlands

Background: Psoriatic arthritis (PsA) is a multifaceted disease.

Objectives: We aimed to evaluate change in medication over time guided by joints, skin, enthesis, low back pain and dactylitis in newly diagnosed PsA patients Methods: Newly diagnosed PsA patients were included in the Dutch Early south-west Psoriatic Arthritis cohoRt (DEPAR) study between August 2013 and March 2016. Initial drug treatment and escalation of therapy were described for all patients. Drivers of treatment changes in the first year were evaluated by mixed Table 1 Multivariable mixed effects ordered|ordinal logistic regression of treatment change over time in early PsA

Covariates Odds Ratio $95 \% \mathrm{Cl}$

\section{covariates}

Swollen joint count (per joint)
Tender joint count(per joint)
Tender entheses (per enthesis) BASDAI (per point)

Dactylitis Index (per point)

timepoints (baseline reference)

3 months
6 months
9 months
12 months
initial starting values ( no dmard reference)

$$
\begin{aligned}
& 3 \text { months } \\
& 6 \text { months } \\
& 9 \text { months }
\end{aligned}
$$$$
\text { erence) }
$$$$
\text { other sdmards }
$$$$
\text { methotrexate subcutaneous }
$$$$
\text { leflunomide }
$$$$
\text { biolegical dmards* }
$$

mixed effects parameters

random slope random intercept

in bold $\mathbf{p}<0.05$; *biological dmards were TNF inhibitors

$\begin{array}{lll}1.14 & 1.06 & 1.24 \\ 0.98 & 0.94 & 1.02 \\ 1.06 & 0.94 & 1.19 \\ 1.05 & 0.97 & 1.15 \\ 1.05 & 1.00 & 1.09 \\ & & \\ 1.55 & 1.01 & 2.37 \\ 1.25 & 0.78 & 2.02 \\ 0.45 & 0.25 & 0.81 \\ 1.52 & 0.79 & 2.91 \\ & & \\ 0.05 & -0.52 & 0.62 \\ 0.49 & -0.08 & 1.07 \\ 4.67 & 3.95 & 5.38 \\ 5.32 & 4.57 & 6.08 \\ 6.23 & 5.42 & 7.05 \\ & & \\ 0.02 & 0.01 & 0.06 \\ 8.30 & 6.12 & 11.25\end{array}$


ordered ordinal regression with outcome treatment change and variables joints (66/68 count), skin (PASI), entheses (LEI and MASES), dactylitis (LDI) and axial disease (BASDAI)

Results: 323 patients had had baseline assessment in March 2016. Their average age was 50.0 years (SD 13.8) and $49 \%$ were male. $80 \%$ patients had arthritis (19\% monoarthritis, 39\% oligoarthritis and $23 \%$ polyarthritis), $9 \%$ had an enthesitis subtype, $2 \%$ axial disease and $9 \%$ dactylitis. Initial treatment consisted of methotrexate (MTX) $(52 \%)$, in $7 \%$ of other synthetic disease modifying antirheumatic drugs (sDMARDs) and due to treatment of psoriasis $3 \%$ biologicals. Within the different phenotypes MTX was most frequently started in polyarthritis $(84 \%)$ followed by oligoarthritis (63\%), monoarthritis $(33 \%)$ and other phenotypes $(5 \%)$. At 12 months $70 \%(n=148)$ stayed on the initial drug. Of those switched, 9 started MTX, within the initial MTX users $(n=74)$ almost equal percentages stopped, switched to metoject or biological (4\%). A smaller percentage $(2 \%)$ switch to leflunomide. Changes in medication were driven by swollen joint count and the presence of dactylitis (Table 1)

Conclusions: MTX was initiated in about half of the early PsA patients. The majority of patients were kept on the initial treatment strategy in first year. Failure on initial drug led to variation in subsequent drugs with additional start of other sdmards, switch subcutaneuous MTX, to other sdmards or to biological dmards. Treatment change was driven by Swollen Joint Count and presence of Dactylitis. Skin, Enthesis and Axial disease did not play a role in escalating treatment. Disclosure of Interest: None declared

DOI: 10.1136/annrheumdis-2017-eular.5922

\section{FRI0498 OUTCOMES ASSOCIATED WITH ACHIEVEMENT OF VARIOUS TREATMENT TARGETS IN PATIENTS WITH PSORIATIC ARTHRITIS RECEIVING ADALIMUMAB}

J. Smolen ${ }^{1}$, D. Aletaha ${ }^{1}$, D.D. Gladman ${ }^{2}$, Y. Zhang ${ }^{3}$, F. Ganz ${ }^{4} .{ }^{1}$ Medical University of Vienna, Vienna, Austria; ${ }^{2}$ University of Toronto, Toronto Western Hospital, Toronto, Canada; ${ }^{3}$ AbbVie, Inc., North Chicago, United States; ${ }^{4}$ AbbVie, Inc., Baar, Switzerland

Background: Various instruments are currently used for disease activity and outcome assessment in psoriatic arthritis (PsA). Some measures attempt to incorporate the total spectrum of psoriatic disease manifestations [eg, minimal disease activity (MDA)] while others focus on arthritis assessments [eg, disease activity index for PsA (DAPSA)]. Whether in patients (pts) with PsA it is sufficient to primarily consider joint disease aspects remains unclear.

Objectives: To compare DAPSA remission and low disease activity (LDA) with MDA and very low disease activity (VLDA) for the presence of residual abnormalities of the respective composing variables.

Methods: This post hoc analysis included pts with PsA receiving adalimumab (ADA) in one of two multicenter studies: ADEPT was a 24-week (wk), randomized, double-blind, placebo-controlled trial; ACCLAIM was a 12-wk, open-label study conducted in Canada in care settings that reflected usual practice. Frequencies of DAPSA remission/LDA and MDA/VLDA were summarized, and the individual PsA manifestations within these states were assessed. DAPSA was summed from the following continuous variables: swollen (66) and tender (68) joints, pt global assessment (PtGA, cm), pt pain (PP, $\mathrm{cm})$, and C-reactive protein (CRP, $\mathrm{mg} / \mathrm{dL}$ ). DAPSA remission was defined as $\leq 4$ and DAPSA LDA as $>4$ and $\leq 14$. MDA criteria were as follows: $\leq 1$ tender, $\leq 1$ swollen joint, $\leq 1$ entheseal point, $P P \leq 15 \mathrm{~mm}, \mathrm{PtGA} \leq 20 \mathrm{~mm}, \mathrm{HAQ} \leq 0.5$, and PASI $\leq 3$. MDA was calculated as fulfilling 5 of the 7 criteria, and VLDA calculated as fulfilling all 7 criteria. Data were as observed.

Results: Among 151 pts receiving ADA in ADEPT, 33 (22\%) each achieved DAPSA remission and LDA at wk 24, and $20(14 \%)$ and $11(7 \%)$ achieved MDA and VLDA, respectively. Pts achieving DAPSA LDA appeared to mirror those in MDA, with the exception of experiencing numerically higher PP, PtGA, and PASI scores at wk 24 (Table). Pts in DAPSA LDA did experience numerically lower SJC when compared with the MDA achievers, and, like MDA achievers, displayed little residual enthesitis. Only VLDA, but not MDA, could match the stringency of DAPSA remission, a finding that was confirmed through analysis of the ACCLAIM cohort.

\begin{tabular}{|c|c|c|c|c|c|c|c|c|}
\hline \multirow[b]{2}{*}{ Variable } & \multicolumn{2}{|c|}{$\begin{array}{l}\text { DAPSA LDA } \\
\text { (>4- } \leq 14)\end{array}$} & \multicolumn{2}{|c|}{$\begin{array}{c}\text { DAPSA Remission } \\
(\leq 4)\end{array}$} & \multicolumn{2}{|c|}{$\begin{array}{c}\text { MDA } \\
\text { (5 of } 7 \text { criteria) }\end{array}$} & \multicolumn{2}{|c|}{$\begin{array}{c}\text { V.DA } \\
\text { (all } 7 \text { criteria) }\end{array}$} \\
\hline & $\begin{array}{c}\text { ADEPT } \\
n=33\end{array}$ & $\begin{array}{c}\text { ACCLAIM } \\
n=37\end{array}$ & $\begin{array}{c}\text { ADEPT } \\
n=33\end{array}$ & $\begin{array}{c}\text { ACD.AIM } \\
n=7\end{array}$ & $\begin{array}{l}\text { ADEPT } \\
n=20\end{array}$ & $\begin{array}{c}\text { ACCLAIM } \\
n=32\end{array}$ & $\begin{array}{l}\text { ADEPT } \\
n=11\end{array}$ & $\begin{array}{c}\text { ACQ.AIM } \\
n=9\end{array}$ \\
\hline TIC, 0-78 & $3.1 \pm 2.96$ & $2.0 \pm 1.80$ & $0.3 \pm 0.73$ & $0.1 \pm 0.38$ & $3.4 \pm 5.85$ & $5.1 \pm 5.49$ & $0.1 \pm 0.30$ & $0.2 \pm 0.44$ \\
\hline $\operatorname{SIC}, 0-76$ & $1.7 \pm 2.00$ & $2.4 \pm 2.53$ & $0.7 \pm 1.36$ & $0.3 \pm 0.49$ & $4.0 \pm 7.97$ & $4.8 \pm 4.31$ & $0.1 \pm 0.30$ & $0.2 \pm 0.44$ \\
\hline $\begin{array}{l}\text { Pain, } 100 \\
\text { mm VAS }\end{array}$ & $\begin{array}{l}17.8 \pm \\
13.28\end{array}$ & $\begin{array}{l}18.9 \pm \\
16.66\end{array}$ & $1 \pm 4.38$ & $3.1 \pm 3.89$ & $8.9 \pm 7.03$ & $\begin{array}{l}14.3 \pm \\
14.55\end{array}$ & $4.8 \pm 3.92$ & $4.9 \pm 4.59$ \\
\hline $\begin{array}{l}\text { PtGA, } 100 \\
\text { mm VAS }\end{array}$ & $\begin{array}{l}17.2 \pm \\
11.92\end{array}$ & $\begin{array}{l}18.9 \pm \\
18.02\end{array}$ & $3.7 \pm 4.09$ & $1.9 \pm 2.67$ & $8.9 \pm 7.07$ & $\begin{array}{l}15.6 \pm \\
20.35\end{array}$ & $4.3 \pm 3.64$ & $4.4 \pm 4.88$ \\
\hline $\mathrm{CRP}, \mathrm{mg} / \mathrm{dL}$ & $0.4 \pm 0.77$ & $1.0 \pm 0.99$ & $0.2 \pm 0.18$ & $1.1 \pm 0.79$ & $0.3 \pm 0.30$ & $1.0 \pm 1.27$ & $0.2 \pm 0.16$ & $1.6 \pm 0.97$ \\
\hline PASI & $2.5 \pm 5.24$ & $1.7 \pm 1.47$ & $0.6 \pm 1.40$ & $1.3 \pm 0.58$ & $0.7 \pm 0.59$ & $2.0 \pm 3.02$ & $0.3 \pm 0.34$ & $1.2 \pm 0.55$ \\
\hline HAQ-DI & $0.4 \pm 0.46$ & $0.3 \pm 0.47$ & $0.1 \pm 0.39$ & $0.2 \pm 0.34$ & $0.2 \pm 0.40$ & $0.2 \pm 0.35$ & $0.0 \pm 0.12$ & $0.0 \pm 0.09$ \\
\hline Enthesitis & $0.1 \pm 0.40$ & $0.1 \pm 0.28$ & $0.1 \pm 0.24$ & $0.1 \pm 0.38$ & $0.2 \pm 0.37$ & $0.2 \pm 0.37$ & $0.0 \pm 0.00$ & $0.1 \pm 0.33$ \\
\hline $\begin{array}{l}\Delta m T S S, 0- \\
570\end{array}$ & $\begin{array}{l}-0.1 \pm \\
1.30\end{array}$ & N/A & $\begin{array}{c}-0.2 \pm \\
0.70\end{array}$ & $\mathrm{~N} / \mathrm{A}$ & $\begin{array}{c}-0.5 \pm \\
2.20\end{array}$ & $\mathrm{~N} / \mathrm{A}$ & $\begin{array}{c}-0.1 \pm \\
0.51\end{array}$ & N/A \\
\hline
\end{tabular}

DAPSA, disease activity index of psoriatic arthritis, MDA, minimal dise ase activity, VLDA, very low disease activity, TIC, tender joint count based on 78 joints; SJC, swollen joint count based on 76 joints, mm, millimeter; VAS, visual analos scale; PtGA, patient global asse ssment of dise ase activity; CRP, C-reactive protein; mg, milligram; dL, deciliter; PASI, psoriasis activity score index; HAQ-DI, health assessment questionnaire disability index; $m$ TSS, modified total Sharp score
However, VLDA allowed for numerically higher residual PP and PtGA levels when compared with DAPSA remission. Importantly, residual enthesitis did not differ among pts achieving DAPSA remission or VLDA. Irrespective of disease activity assessment, pts receiving ADA displayed little to no radiographic progression. Conclusions: In the ADEPT and ACCLAIM cohorts, pts who achieved DAPSA remission or VLDA demonstrated similar outcomes with respect to the individual components of both scores, despite the omission of several of these within the DAPSA. Given the DAPSA's continuous nature, its use may offer a good alternative to fulfillment of the VLDA criteria, but these results require confirmation in different pt populations.

Acknowledgements: AbbVie: study sponsor, contributed to design, data collection, analysis, interpretation, and abstract writing, review, and approval. Medical writing: Ben Wolfe of AbbVie.

Disclosure of Interest: J. Smolen Grant/research support from: AbbVie, Inc., Consultant for: AbbVie, Inc., D. Aletaha Grant/research support from: AbbVie, Inc., Pfizer, Grünenthal, Merck, Medac, UCB, Mitsubishi/Tanabe, Janssen, and Roche, Consultant for: AbbVie, Inc., Pfizer, Grünenthal, Merck, Medac, UCB, Mitsubishi/Tanabe, Janssen, and Roche, D. Gladman Grant/research support from: AbbVie, Inc., Amgen, Bristol-Myers Squibb, Celgene, Eli Lilly, Janssen, Pfizer, Novartis, and UCB, Y. Zhang Shareholder of: AbbVie, Inc., Employee of: AbbVie, Inc., F. Ganz Shareholder of: AbbVie, Inc., Employee of: AbbVie, Inc. DOI: 10.1136/annrheumdis-2017-eular.3762

\section{FRI0499 REAL-WORLD STUDY ON THE PATTERNS AND COST OF TREATMENT FAILURE IN PATIENTS WITH PSORIATIC ARTHRITIS USING US CLAIMS DATA}

K. Price ${ }^{1}$, E. Alemao ${ }^{1}$, L. Burns ${ }^{1}$, Z. Guo ${ }^{1}$, V. Anupindi ${ }^{2}$, S. Goday ${ }^{3}$. ${ }^{1}$ Bristol-Myers Squibb; ${ }^{2} \mathrm{Mu}$ Sigma, Princeton, United States; ${ }^{3} \mathrm{Mu}$ Sigma, Bangalore, India

Background: Current treatments for psoriatic arthritis (PsA) are associated with a range of limitations, e.g. side effects, safety concerns and inadequate efficacy. The economic burden of biologic (b)DMARD failure among patients (pts) with PsA is thought to be substantial, ${ }^{1}$ but there is a need to quantify this formally.

Objectives: To evaluate PsA treatment failure (i.e. discontinuation and switching rates) in a US managed care setting and its economic consequences.

Methods: Pts aged $\geq 18$ years with 2 diagnosis codes for PsA and 1 claim for a bDMARD from 1 Jan 2007 to 31 Mar 2015 in the Truven Health MarketScan ${ }^{\circledR}$ Database (Commercial and Supplemental Medicare) were eligible for the study. Pts were considered incident if they did not have a PsA diagnosis or a bDMARD prescription during 1 year prior to first PsA diagnosis in the study period, and as prevalent otherwise. Pts had a 1-year follow-up from first PsA diagnosis in the study period. The percentages of pts discontinuing a drug, switching to another drug or continuing on the same drug for 1 year from first date of treatment were reported. Healthcare costs for 1 year from initiation of the first bDMARD, (medical and drug costs associated with treatment failures) were reported as cost per-pt-per-month (PPPM), and a generalized linear model was used to analyse the cost after controlling for various demographic variables.

Results: Of the 18,632 pts treated with a bDMARD, $1298(6.97 \%)$ were incident and $17,334(93.03 \%)$ prevalent. Almost half $(n=8994 ; 48.27 \%)$ of the pts continued on the index bDMARD for 1 year. Treatment failed for the remaining pts, with 7852 (42.14\%) discontinuing, and 1630 (8.75\%; overlap $\leq 30$ days between drugs) and 156 (0.84\%; overlap > 30 days) switching. In the prevalent group, $8754(50.50 \%)$ pts continued on the index drug, 7043 (40.63\%) discontinued, and 1399 (8.07\%; overlap $\leq 30$ days) and 138 (0.79\%; overlap > 30 days) switched to another drug Among incident pts, only 240 (18.49\%) continued, 809 (62.33\%) discontinued and 231 (17.80\%; overlap $\leq 30$ days) and 18 (1.38\%; overlap $>30$ days) switched to another drug. Pts with an overlap $>30$ days were excluded from the analysis. Overall, pts who switched had a higher PPPM total cost $(\$ 3317)$ than those who discontinued $(\$ 2650 ; p<0.0001)$ or continued $(\$ 2708 ; p<0.0001)$. Similar results were observed in the prevalent and incident groups, respectively, with pts who switched incurring a higher PPPM total cost (\$3241 and \$3779) compared with those who discontinued $(\$ 2583$ and $\$ 3237$; both $\mathrm{p}<0.0001)$ or continued $(\$ 2700$ and $\$ 3080$; both $p<0.0001)$. Increasing age (per year) was associated with a $0.57 \%$ higher total cost in the incident group $(p=0.002)$ and with a $0.49 \%$ higher cost in the prevalent group $(\mathrm{p}<0.0001)$. Among prevalent pts, females had a $3.08 \%$ higher cost than males $(p=0.0069)$. The Charlson Co-morbidity Index score predicted a higher cost $(p<0.0001)$ among prevalent but not incident pts.

Conclusions: In a US claims study population of pts with PsA, rates of treatment failure as defined by switching or discontinuation were high. Follow-up costs for pts who switched were higher than for pts who continued or discontinued their medication. Baseline age, female sex and co-morbidities were associated with higher treatment costs.

References:

[1] Taylor PC, et al. Rheumatol Int 2016;36:685-95.

Disclosure of Interest: K. Price Employee of: Bristol-Myers Squibb, E. Alemao Shareholder of: Bristol-Myers Squibb, Employee of: Bristol-Myers Squibb, L. Burns Shareholder of: Bristol-Myers Squibb, Employee of: Bristol-Myers Squibb, Z. Guo Shareholder of: Bristol-Myers Squibb, Employee of: Bristol-Myers Squibb, V. Anupindi: None declared, S. Goday: None declared

DOI: 10.1136/annrheumdis-2017-eular.1476 